\title{
Digital platforms based marketing innovations: new development trends
}

\author{
Alex Krasnov ${ }^{1}$, Valentin Nikonorov ${ }^{1 *}$, and Marina Yanenko ${ }^{1}$ \\ ${ }^{1}$ Peter the Great St. Petersburg Polytechnic University, Institute of Industrial Management, \\ Economics and Trade, 195251 Polytechnicheskaya st. 29, Russian Federation
}

\begin{abstract}
Marketing innovations in the digital economy are considered as the most important factor for the further digital economy growth. The main trends for development of the information and communication technologies market are studied. The basic types of innovations are analyzed. An algorithm for generation of competitive innovative marketing strategies is proposed. A business strategy that takes into account the digital technologies development is supplemented by a number of innovative components. The main lines for generation of a digital platform for marketing activities transformation with subsequent disclosure of the content of each line are indicated. The digital platform design for the marketing activities transformation is developed. There are three cornerstones of this platform are arrangement of interaction with consumers in the digital environment; improvement of digital methods for processing marketing information; automation of planning and implementation of marketing activities. The marketing complex specifics in the digital economy are specified and supplemented.
\end{abstract}

\section{Introduction}

Relevance. The ICT development results in revolutionary changes in the society and the economy, forces to talk about the generation of the information society that differs significantly from the industrial and post-industrial societies. Even now there is a significant contribution of information and communication technologies to the gross domestic product of the Russian Federation.

Foreign specialists also note the ICT importance specifying the need to use new innovative tools for development of economy and marketing such as Internet of things, BigData, Cloud computing, etc. [1,2,3].

Under modern globalization conditions the marketing system turns into an integrated unified system for coordinating supply and demand at all levels of economic ties in the use of tangible and intangible assets. At the same time, the virtualization of market processes, their communication and communicatory integration contribute to generation of an objective hierarchical marketing structure, which, in turn, affects the business processes efficiency.

\footnotetext{
*Corresponding author: Nikanorv@mail.ru
} 
The marketing is developed through multimedia communications: the Internet, call centers, mobile phones, interactive television, etc., which allow to establish individual contacts with customers at a faster rate and at lower cost and to provide long-term aftersales service. Here is the place to especially highlight a number of trends for development of the information and communication technologies (ICT) market, and especially Foresight marketing technologies $[4,5]$ :

1. Growing of the Internet role and influence on economic processes.

2. Companies' focus on the purchase of ready IT tools and solutions.

3. Convergent solutions become more popular when the Internet is connected with mobile devices and IP-telephony.

4. Cloud technologies development and application.

5. DATA-centers organization by domestic companies.

6. Appearance of high-speed communication technologies and Internet access.

7. Individualization of needs satisfaction and customer service personalizing.

8. Internet of things market growth.

9. "Nuclear" growth in a number of social networks including ones of professionals and professionals.

The marketing management that is developed on the basis of media technologies under constant changes in the economy, science, practice requires rethinking, formulating of the conceptual foundations of innovation development. Marketing innovations will play a key role in the development of markets in the global economic space.

\section{Development of marketing innovations}

Under the global competition, innovations make it possible to provide leading positions in world commodity markets and to receive solid financial dividends through the introduction of new technologies. Therefore, the developed countries purposefully support the innovation processes. A share of new or improved technologies containing advanced knowledge or solutions is up to $80 \%$ of GDP growth in the developed countries. At the same time, scientific-and-technical and innovation activities in the Russian Federation are featured by a sharp decline against the innovations development in the world community. The contribution of Russian innovative products to the world bank of innovations is only $0.3 \%$ and tends to further decrease [6]

Therefore, under the sanctions, the transition to an innovation development model is a necessary strategic choice that in mid-term perspective can assist to overcome the production crisis, industry restructuring and market saturating with competitive products. In the long term, such a strategy shall help Russia to restore its position in the developed countries community.

J. Schumpeter interprets the innovations as "a change for the purpose of implementing and using new types of consumer goods, new production and transportation means, markets and forms of industry organization" [7].

The majority of theorists and practitioners in the management adheres to the innovation concept presented by J. Schumpeter. It is also taken as a basis for the development of the regulatory and legal framework for innovations in our country, in the development of innovation concepts, programs, and other strategic documents. There are two main approaches to innovation: 1) as a result of the creative process; 2) the process of innovations implementation.

U. King and D. Cleland mean by innovation a process including generation of a new idea of products, technology, material, management, form of production organization - 
analysis and selection of received proposals; approbation of development in production conditions; mass production and assessment by consumers [8].

According to V. E. Gordin and M. D. Suschinskaya et al. [9] it is possible to identify the main innovation criteria: scientific-technical or social-cultural novelty; practical incarnation; commercial feasibility.

From the above definitions, the following conclusion may be drawn that the specific innovation content composes the changes. These innovations cover a very wide range of activities - from research and development to marketing activities, include both the innovation process itself and its result.

In practice, there are four types of innovation: product, process, marketing and organization.

Product innovation is the introduction to the use (implementation) of a product or service that is new or significantly improved in terms of their properties or methods of use.

Process innovation is the introduction of a new or significantly improved way for product production or delivery.

Organizational innovation is the introduction of a new organizational method in the enterprise business standard, in the organization of workplaces or external relations.

Marketing innovation is the introduction of a new marketing method including significant changes in the product design or packaging, its placement, promotion to the market, or in setting prices [10].

The marketing innovations are aimed at the best satisfaction of the needs of the consumer, opening of new markets or winning of new positions for the enterprise's products on the market for sales increasing.

A distinctive feature of the marketing innovation compared to other changes in marketing tools is the implementation of the marketing method. The digital technologies implementation to solve marketing challenges (consumers' analysis, product selection at the request of individual customers, etc.) can also be considered a marketing innovation.

The digital technologies development stimulates appearances of spatial relationships between enterprises, creates unprecedented abilities in establishing mutually beneficial relations with customers. Due to the rapid spread of wireless networks, smartphones and tablets, mobile applications and cloud computing technologies, there are significant changes in the consumers lifestyle, activation of e-commerce [11].

ICTs create new conditions for market interaction, allow to significantly increase the level of consumers' confidence. The overwhelming majority of authors agree that ICT fundamentally change the company's external and internal marketing environment, approaches to marketing research, analysis of markets and competitors, development of marketing strategies and marketing programs [12].

It seems that the implementation of digital technologies in marketing activities will mainly facilitate the transition in communication with a client from the impressions to the creation of its constant involvement in the firm's activities. The effect is created by channels and means of digital technologies due to new ways to attract consumers and to increase a rate of communication with them.

The results of our research $[12,13,14]$ allow to conclude that most of the surveyed companies (more than $70 \%$ ) in one form or another actively use marketing innovations in their daily marketing activities

The innovative marketing activity of the enterprise is based on constant work with various sources of information, knowledge about technologies, practical experience, available and accessible human and financial resources.

Marketing innovations research includes the analysis of possible response of potential consumers to the innovations, the analysis of innovation from the point of view of the 
consumer, as well as comprehensive analysis of the innovative market environment. It shall be ensured that the scientific, technical and economic information relevant to the marketing strategy development is monitored continuously and on its basis corrections are made both to the strategic decisions of the firm and to the tactical means for achieving the priority objectives.

To generate competitive innovative marketing strategies, we propose the following algorithm.

Stage I. Identification of the main trends affecting the business environment.

1. Analysis of trends in the development of the world and Russian economy.

2. Analysis of trends in the industry development.

3. Analysis of trends in the business environment development.

4. Analysis of marketing innovations.

Stage II. Definition of prospective directions of innovation development of the enterprise.

Stage III. Assessment of the prospects for integration in the innovation environment.

1. Assessment of participation in government programs

2. Assessment of participation in federal targeted programs.

3. Assessment of participation in design and survey work.

4. Assessment of participation in the generation of the knowledge economy.

IV. Generation of the strategy for participation in the innovation process.

V. Choice of innovation tools for marketing strategy implementation

1. Mobile technologies.

2. BigData technologies.

3. Geoinformational technologies.

4. Video analytics technologies.

VI. Generation of competitive innovation marketing strategy.

The algorithm can work both at the enterprise level and at the industry level.

Its main features are that to reduce the costs and time of marketing research, the economic phenomena concept is used that allows moving from time-consuming and longterm studies of environmental factors to the formation of a generalized description of the processes taking place in the economy and the enterprise business environment. Identification of the main trends affecting the business environment allows to determine the prospective lines of innovation enterprise development and to assess the prospects of its integration in the innovation environment.

Generation of the innovation marketing strategy is impossible without the use of innovation tools, with the help of which the program will be implemented. Along with the marketing innovations listed, for example, in [12,13,14], we consider the innovative marketing tools based on the use of mobile, BigData, Internet of Things technologies, etc., and being not yet sufficiently described in the marketing literature are prospective .

\section{Further learning of the concepts of organization digital platform development and management of the organization marketing activities}

According to M. B. Yanenko and M. E Yanenko.who studied mobile technologies in marketing services in [14], the business strategy considering the development of mobile technologies shall include such innovation components as:

- adaptation of the corporate site, promo-sites for mobile devices; 
- adaptation of the existing company services for mobile devices and creation of special applications;

- development of the company's IT infrastructure to ensure high-quality, stable communications;

- the maximum coverage of potential buyers and constant information impact on them;

- increase the volume and quality of on-line advertising;

- provision of the client's access to the account from any device;

- new pricing policy and loyalty programs for customers viewing on-line advertising and buying it from mobile devices;

- individualization of work with a client and strengthening of feedback, etc.

The authors proposed the digital platform design for the marketing activities transformation (Fig. 1).

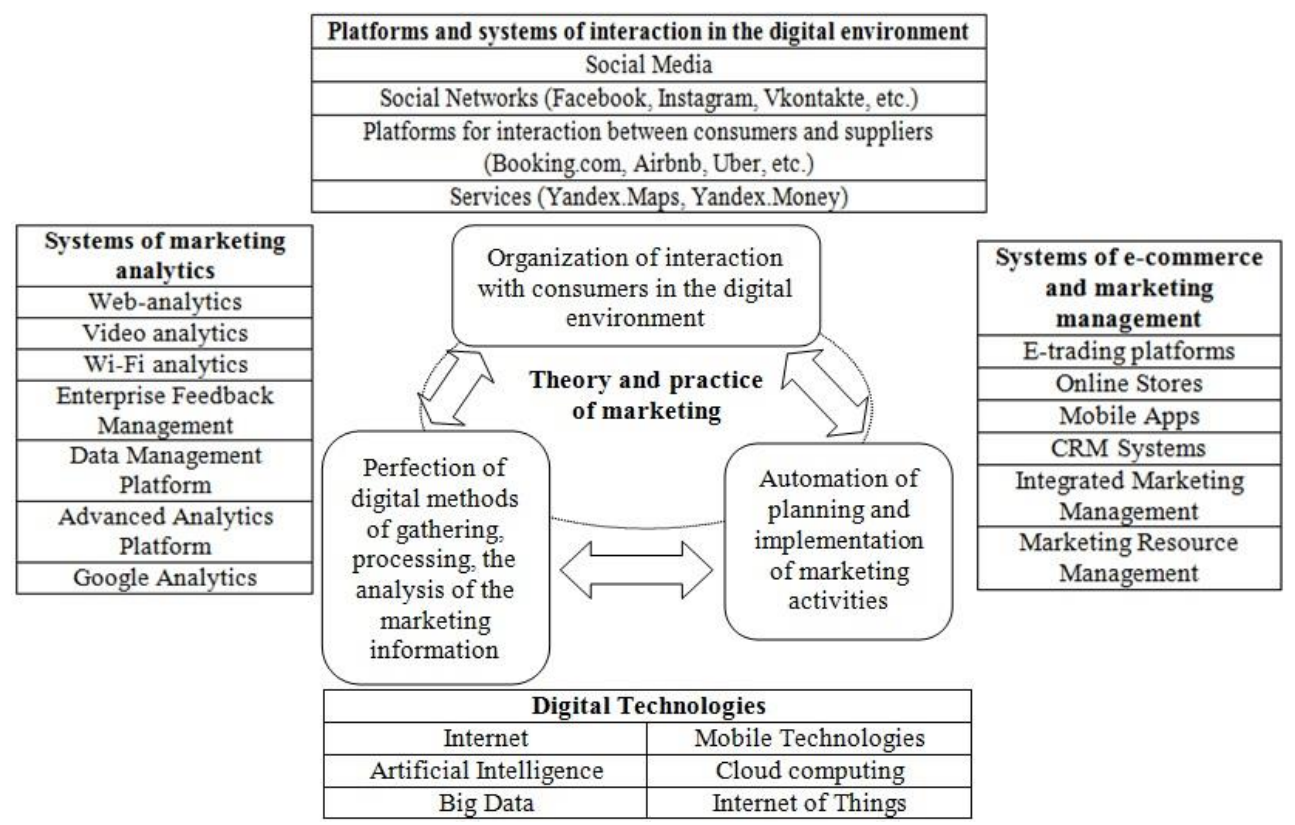

Fig. 1. The main elements of marketing innovations based on the digital platforms.

Based on the marketing theory and practice, it is possible to identify the following basic lines for generation of the digital platform for marketing activity transformation

- improvement of digital methods for collection, processing, analyzing of marketing information;

- arrangement of interaction with consumers in the digital environment;

- automation of planning and implementation of marketing activities.

The first line is improving the methods for collection, processing, analyzing of marketing information; it is aimed primarily at creating systems of marketing analytics, specialized tools for marketing data analysis. Web analytics, video analytics, Wi-Fi analytics, etc. can be used as an example.

The second line of digital platform generation is the improvement of arrangement of interaction with consumers in the digital environment.

Development of marketing activities under marketing functions digitizing implies, along with such conventional channels as Internet advertising, direct mailings, mobile 
communication, etc., the use of social media, social networks (Facebook, Instagram, Classmates, etc.), digital platforms of interaction of consumers and suppliers (Booking, Momondo), various services [15].

Identification of the automation of planning and implementation of marketing activities, and the development of e-commerce and marketing management systems as a third line is due to that, along with the electronic trading platforms, on-line stores, mobile applications, CRM systems widely used in practice and already described in the marketing literature, there are new marketing activities automation systems such as Integrated Marketing Management, Marketing Resource Management.

Under real conditions there is a continuous process of integration of various computer and software products aimed at creating platforms and systems of continuous interaction between the consumers and the suppliers. In this case, the conventional cycle of marketing activities including marketing research, planning and implementation of marketing activities is implemented as software products that provide instant system response to changing customer requests.

In terms of the generation of the digital platform for marketing activities management, it is necessary to clarify certain provisions of the marketing theory.

In particular, the marketing complex elements (Fig. 2) will have a number of features that characterize the abilities of interaction in the digital environment (for more details see our paper 12,13).

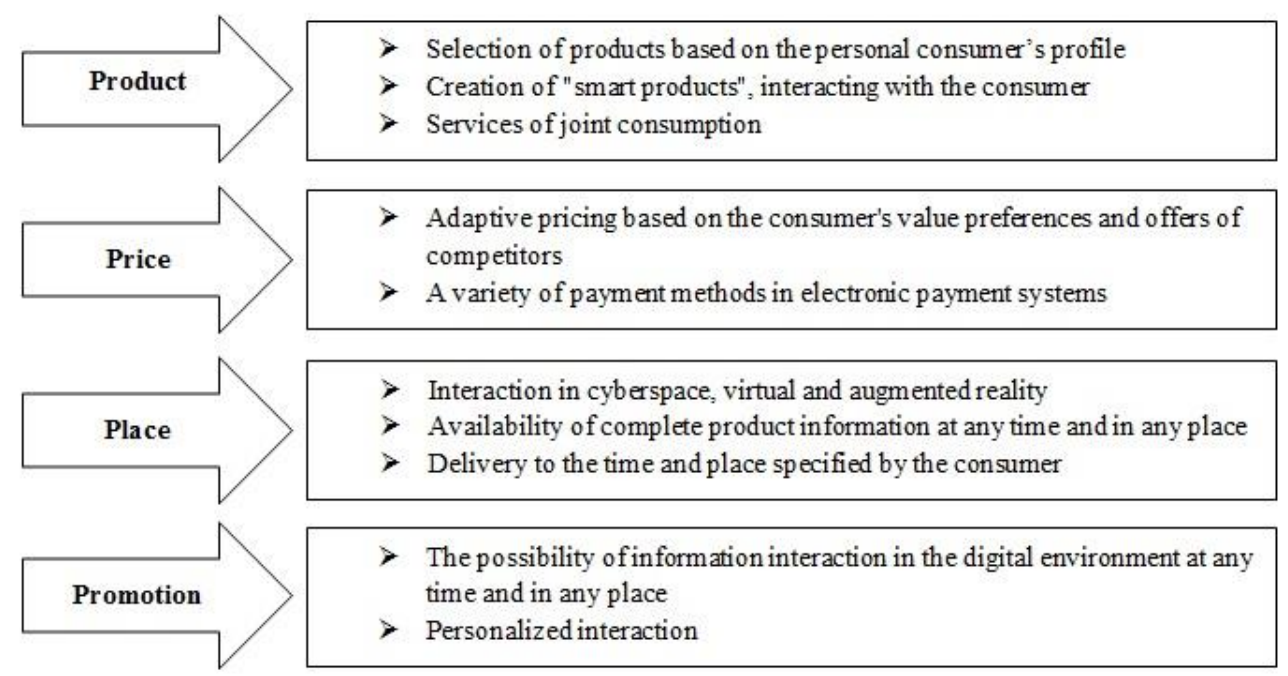

Fig. 2. The marketing complex specifics in the digital economy.

The above considerations show that the transformation of the marketing activities management in the digital economy is complex and requires an in-depth analysis of the practice of using the digital technologies, rethinking a number of key theoretical marketing provisions.

The main challenges for generation of the organization digital platform and marketing activities management shall include the following:

- onrush of digital technologies; computer technologies grow and change faster than the business can adapt to them;

- explosive growth of data volumes; they are extremely difficult to process to find data that can help make the right decisions.

- increased competition. 
Thus, the creation of the organization digital platform and marketing activities management is not a one-off event, but one of the key innovation lines of the business development strategy, a continuous process that allows monitoring environmental changes and using the digital technologies to strengthen competitive positions in the digital economic space.

The main point of the marketing activities management transformation is the accelerated application of rapidly developing digital technologies to solve key marketing problems such as: competitive situation analysis; prices monitoring; activities to promote goods and services in a virtual environment; presentation of goods and services to customers; the desire to involve the consumer in the interaction process, that is, during identifying and satisfying the needs.

The lag in the transfer of functional and technological subdivisions to the use of digital technologies can lead to additional costs associated with loss of consumers, decrease in the sales of goods or services provided.

The digital technologies development, innovation economy building will require significant changes in the marketing activities arrangement. Among the most significant changes there are the following.

1. Participation in the development (as a customer) of new analysis tools and subsequent application of these tools allowing to process large amount of marketing information.

2. Search for optimal combinations of digital and classical marketing methods.

3. Ideas generation, super-fast (thanks to the digital technologies) spread of the generated ideas among a large number of potential consumers.

\section{Conclusions}

The analysis of extensive literature, publications on information resources and technologies in marketing, statistical data makes it possible to obtain the following important results:

1. Knowledge and skillful use of information technologies, resources, systems provide the unlimited possibilities for the successful work of the marketer allowing him/her to navigate the information space, to find and effectively use valuable information to achieve the firm's goals.

2. The skills of handling information can become an important competitive advantage of a marketer in the modern labor market.

3. Expanding use of the digital technologies in marketing processes is explained by the desire of enterprises to increase competitiveness and profits through effective processing of marketing information and creation of new business lines. A systematic approach to the use of ICT becomes an important competitive advantage of the company, allowing it to occupy a leading position in the market. The changes in the elements of the marketing complex allow to identify and include innovation measures in the marketing strategy aimed at increasing economic efficiency and securing the company's long-term competitive advantages. 


\section{References}

1. New Skills for the Digital Economy [online], Available at: http://dx.doi.org/10.1787/5jlwnkm2fc9x-en (2017)

2. The Internet of Things [online], Available at: http://dx.doi.org/10.1787/5jlwvzz8td0nen (2017)

3. Cloud Computing: The Concept, Impacts and the Role of Government Policy [online], Available at: //dx.doi.org/10.1787/5jxzf4lcc7f5-en (2017)

4. G. L. Bagiev, A. A. Dligach. Yu. N. Soloviyova, Marketing foresight technologies Relationship marketing: system reflexive marketing. Benchmarking.Competence management. Value measurement and assessment (Asterion, Saint Petersburg, 2016)

5. V.N. Naumov, Information and communication technology markets and sales arrangement (INFRA-M, Moscow, 2017)

6. Yu. Samsonov, Maket of Russian innovations [online], Available at: http://www.center-inno.ru/materials/library/06-2 (2015)

7. J. Schumpeter, TheTheory of Economic Development (Progress, Moscow, 1983)

8. U. King, Cleland Strategic planning and policy (Progress, Moscow, 1982)

9. V. E. Gordin, M. D. Sushinskaya, Service management (Pub. House "Business-Pressa", Saint Petersburg, 2007)

10. Oslo management, Recommendations for collection and analysis of innovation data ZISN, Moscow, 2010)

11. E. V. Popov, Minieconomic institution evolution (Nauka, Moscow, 2007)

12. M. B. Yanenko, M. E. Yanenko, Izvestiya of Ural State University of Economics, 2 (24) (2009)

13. M. B. Yanenko, M. E. Yanenko, Methodology for formation of innovative marketing strategies under digital technologies introduction (Saint Petersburg State University of Economics, Saint Petersburg, 2015)

14. M. B. Yanenko, M. E. Yanenko, Modern economic problems, 2 (50) (2014)

15. E-mail marketing mobilization [online], Available at: https://subscribe.ru/archive/media.vox/201410/30171621.html (2015) 